\title{
Health profiles of First Nations children living on-reserve in Northern Ontario: a pooled analysis of survey data
}

\author{
Mary Jo Wabano MHK, Leslie F. McGregor BA, Roger Beaudin BA, Diane Jacko BA, \\ Lorrilee E. McGregor PhD, Sabine Kristensen-Didur BA, Debbie Mishibinijima BA, Koyo Usuba MHK, \\ Nancy L. Young PhD
}

\section{Abstract}

Background: The Aboriginal Children's Health and Well-Being Measure (ACHWM) was developed to enable Aboriginal health leaders to gather information on the health of children at a local community level. This paper aims to describe the typical health profiles of First Nation children living on traditional territory as a reference to assist in the interpretation of ACHWM scores.

Methods: Three First Nations in Ontario, Canada, gathered health data from children using the ACHWM administered on Android tablets between 2013 and 2015. The survey data were previously analyzed to inform local health planning. These survey data were pooled to describe the distribution of ACHWM summary and quadrant scores from a larger sample and inform interpretation of ACHWM scores.

Results: ACHWM data from 196 participants (aged 7.6 to $21.7 \mathrm{yr}$ ) across 3 communities were included in the pooled sample. ACHWM summary scores ranged from 39.8 to 98.7 with a mean of 74.1 (95\% confidence interval [Cl] $72.5-75.7)$ and a maximum of 100. Strengths were reported in the spiritual (mean 78.7, 95\% Cl 76.7-80.8), physical (mean 77.1, 95\% Cl 75.1-79.0) and emotional (mean $74.4,95 \% \mathrm{Cl} 72.5-76.3$ ) quadrants. The greatest opportunity for improvement was in the mental (cognition) quadrant (mean $61.6,95 \%$ Cl 56.9-63.4).

Interpretation: This paper presents initial estimates for child health scores based on self-report from a large sample of First Nations children living on reserve. These results establish benchmarks to aid interpretation of the ACHWM scores in these and other communities and contexts in the future.

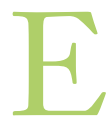

vidence-based health care is considered a gold standard for clinical practice, policy and planning, ${ }^{1,2}$ but it is not yet an option for many Aboriginal communities in Canada. (Note that the term Aboriginal is used in this paper, rather than Indigenous, on the basis of guidance from the community-based Aboriginal Children's Health and Well-being Measure Advisory Committee. Aboriginal peoples include First Nations, Inuit and Métis.) First Nations health directors require local health data that extend beyond the biomedical. From their perspectives, the most meaningful data reflect First Nations models of health and are relevant to Aboriginal cultures and contexts. Decision-makers who are responsible for Aboriginal children's health are challenged when searching for relevant health statistics, because most available statistics are based on illness (e.g., rates of diabetes $\left.{ }^{3,4}\right)$ rather than wellness. When health data are presented, the results are typically aggregated at the provincial or national level..$^{5}$ As a result, there is a critical absence of health data that are relevant at the local level. ${ }^{6-8}$
While national and provincial data are helpful in identifying problems, this information is far less helpful in identifying solutions. Given that each Aboriginal population is distinct (culturally, politically and geographically), the assumption that decisions can be made on the basis of provincial or national estimates is inherently flawed.

There have been several calls for solution-focused action to promote health among Aboriginal children in Canada. ${ }^{9-12}$

Competing interests: The copyright for the Aboriginal Children's Health and Well-Being Measure (ACHWM) is held by Mary Jo Wabano, Nancy Young and Stephen Ritchie. The ACHWM is shared with Aboriginal communities and agencies free of charge. No other competing interests were declared.

This article has been peer reviewed.

Correspondence to: Nancy Young, nyoung@laurentian.ca CMAJ Open 2019. DOI:10.9778/cmajo.20180128 
Data aggregated at the local community level are essential to the planning and delivery of cost-effective, high-impact programs and services, to address critical Aboriginal child health inequities.

The Aboriginal Children's Health and Well-being Measure (ACHWM) was developed in response to a request from 1 community and a recognized gap in the literature. The aim of the ACHWM is to provide First Nations communities and Aboriginal agencies a tool to gather local child health data. ${ }^{13}$ It was developed through a community-university collaboration $^{13}$ with guidance from a local advisory committee, who shared the medicine wheel framework shown in Figure 1 with us as the framework ${ }^{14}$ for the measure's development. Items for the ACHWM were generated using focus groups and photovoice methods with children from Wiikwemkoong Unceded Territory and later validated across other First Nations, Inuit and Métis populations. ${ }^{15}$ A key goal during the development process was to ensure that the ACHWM was reliable, feasible and sustainable and furthermore that the tool would be relevant to inform local health planning in Wiikwemkoong and other Aboriginal communities in Canada.

Data gathered by the ACHWM are owned by the community, thus respecting First Nations' rights to self-determination and enabling solutions to be generated from within each community. ${ }^{17}$ This measure has been thoroughly tested with First Nations children in Wiikwemkoong, as well as with Métis and Inuit children in urban contexts. ${ }^{15}$ The results have demonstrated the validity of the self-reported ACHWM for children 8 to 18 years of age in comparison with the Pediatric Quality of Life Inventory (PedsQL; $r=0.52)^{18}$ and its reliability (test-retest intraclass correlation coefficient $=0.94) .{ }^{19}$

The aim of this paper is to establish typical ACHWM health profiles for First Nations children living on-reserve, to assist in the interpretation of ACHWM scores.

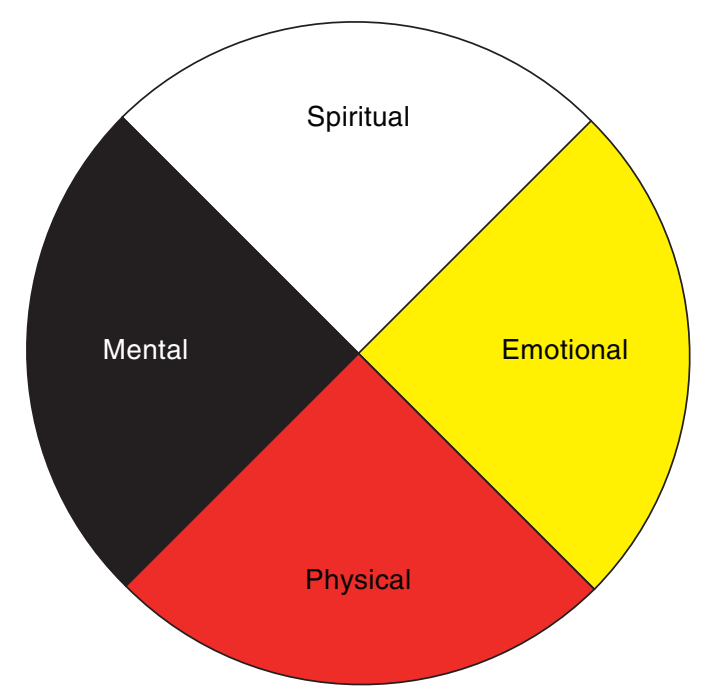

Figure 1: Medicine wheel.

\section{Methods}

\section{Setting and design}

We conducted a secondary analysis of data from 3 Anishinaabe communities in the Manitoulin Island region of northern Ontario, Canada, who completed population-level cross-sectional surveys between August 2013 and March 2015, in collaboration with Laurentian University. The participating communities were Wiikwemkoong Unceded Territory (August 2013 to August 2014), M'Chigeeng First Nation (October to November 2014) and Whitefish River First Nation (December 2014 to March 2015) (Figure 2). Eligible participants were band members between 8 and 18 years of age who were living on-reserve and did not have any particular illness. Some participants were over 18 years of age but were included in the analysis because they were in high school. This is in keeping with a First Nations perspective on youth, which extends up to 25 years of age. Participants were recruited by community researchers at a variety of locations: schools, the local health centre and community events. The community researchers obtained informed consent from all participating children and from their parents when applicable. No direct incentives were offered, but in keeping with local tradition a draw was held in 1 community for a bicycle.

\section{Data sources}

The primary outcome measure in this analysis was the ACHWM, which was implemented in small groups in each community by local community researchers. The ACHWM contains 62 multiple-choice questions that focus on children's feelings and perceptions of their own health (the ACHWM is not included in this article but is available upon request via www.ACHWM.ca). Questions relate to 4 quadrants of health: spiritual (e.g., traditional language), emotional (e.g., laughing and have fun), physical (e.g., making healthy choices) and mental (e.g., staying focused on schoolwork during class). It was designed to be completed independently by children (aged 8 to $18 \mathrm{yr}$ ) using Android tablets. The use of tablets enhanced the survey's appeal to children while eliminating the need for data entry and permitted a text-to-speech option that enabled those with low literacy levels to participate.

The ACHWM generates a summary score based on all 62 items and 4 quadrant (or subscale) scores: spiritual, emotional, physical and mental (cognitive) health. Scores range from 0 to 100 , with higher scores indicating better health.

The ACHWM data were gathered to inform local health planning. In addition to the goal of generating communitylevel data, there was a need to support children who shared their health concerns. A screening algorithm embedded in the ACHWM was applied to identify worrisome response patterns and ensure respondents were connected to the appropriate support services. ${ }^{16}$ After completion, a local mental health worker assessed children's needs for support and made immediate referrals. This is a best practice when surveying vulnerable children, respects the children's voices and ensures their safety. More information is available at www.ACHWM.ca.

Deidentified data gathered through the surveys were uploaded to a secure server, REDCap (Research Electronic 


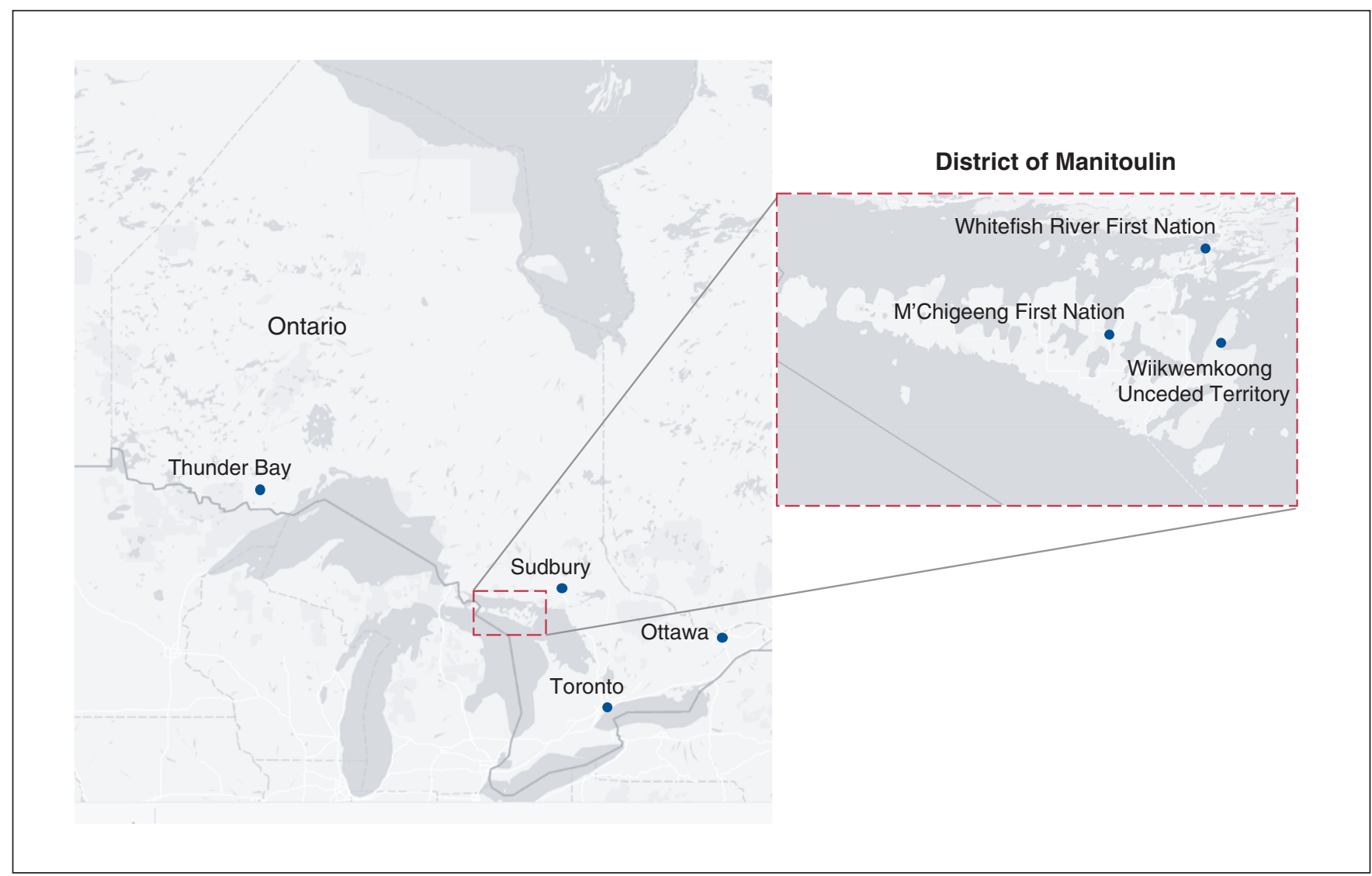

Figure 2: Location of participating communities.

Data Capture), ${ }^{20}$ hosted at Laurentian University. Detailed confidential reports on community-level data were presented to each individual community, 2 years before this analysis. These community reports were not published. Permission was obtained from community health leaders (M.J.W., L.F.M. and R.B.) for this pooled analysis.

\section{Statistical analyses}

The data from all communities were pooled to produce an aggregate picture of child health and to ensure cell sizes were sufficient to protect the confidentiality of participants. Means, standard deviations (SDs) and 95\% confidence intervals (CIs) were computed for the ACHWM summary score and each of the ACHWM quadrant scores: spiritual, emotional, physical and mental health. Graphs were created to show the distribution of the ACHWM summary scores and quadrant scores. Summary scores and quadrant scores were computed as the average of all items. Summary and quadrant scores were not produced when more than $25 \%$ of responses were missing.

\section{Additional exploratory analyses}

The effect of age and sex on summary and quadrant scores was explored using linear regression. The concept of balance is particularly important in the Anishinaabek conceptualization of health; thus, we sought to explore balance within this pooled sample. According to traditional teachings, balance is reflected when all aspects of health and wellness are equally strong. However, these teachings also recognize that the goal is not to achieve perfect balance at all points in time but to move toward better balance. This was displayed for children using an ACHWM balance app that produced a diagram, based on each child's scores presented in the format of a medicine wheel, in which the strength of each quadrant is reflected in the radius of the quadrant. To describe the degree of balance statistically, we computed a balance score for each individual as the within-person standard deviation, as previously described by Tractenberg and Pietrzak. ${ }^{21}$ We recognize that this is not the traditional way of assessing balance, but we are using it as an indicator of balance. On this balance scale, lower numbers indicate optimal balance. We produced a histogram of the distribution of balance scores as a guide to interpret balance scores in the future.

Finally, we used the pooled data to estimate the proportion of participants identified through the ACHWM screening process as needing further health support on the basis of the ACHWM and confirmed by local mental health workers. All analyses were performed using Stata version 14 (Stata Statistics/Data Analysis, StataCorp LP).

\section{Ethics approval}

This study was approved by the Laurentian University Research Ethics Board and the Manitoulin Anishinaabek Research Review Committee. ${ }^{22}$ To respect community protocols, a Band Council Motion (BCM) was approved in 
Wiikwemkoong in the spring of 2013 (BCM 418-2013), in Whitefish River in October 2013 (BCM 10-27-13) and in M'Chigeeng in July 2014 (BCM 44.13).

\section{Resullts}

A total of 196 First Nations children participated in the community surveys: 124 in Wiikwemkoong, 32 in M'Chigeeng and 40 in Whitefish River. This sample comprised approximately $25 \%$ of the target population. ${ }^{23}$ In this group, $52 \%$ were girls and $48 \%$ were boys. They ranged in age from 7.6 to 21.7 years, with a mean age of 13.6 (SD 3.69) years. Additional details on the participants' characteristics are presented in Table 1. No participants were excluded because of missing data; missing data were considered to be missing at random. For the purpose of comparing the data from this study with other health reports, children were asked to provide a global health rating. The global health ratings in this sample were as follows: $16 \%$ excellent, $24 \%$ very good, $44 \%$ good, $11 \%$ fair and $5 \%$ poor health. Of the participants aged $12-17$ years, $14 \%$ reported being in excellent health.

\section{Aggregate results}

ACHWM summary scores ranged from 39.8 to 98.7 with an average of 74.1 (SD 11.45, 95\% CI 72.5-75.7), where the maximum range was 0 (worst) to 100 (best). The summary score distribution is shown in Figure 3; it was slightly skewed $(-0.68)$ but not kurtotic (3.38). On the basis of these parameters, parametric statistics were considered to be appropriate.

The strengths, as reported from the perspective of these children, were in the children's spiritual, physical and emotional quadrants, with mean scores of 78.7 (SD $14.51,95 \%$ CI $76.7-$ 80.8), 77.1 (SD 13.90, 95\% CI 75.1-79.0) and 74.4 (SD 13.62, 95\% CI 72.5-76.3), respectively. The greatest opportunity for improvement was in the mental health quadrant, with a mean of 61.6 (SD 12.61, 95\% CI 56.9-63.4). Note that the mental

\begin{tabular}{|c|c|c|c|}
\hline Community & $\begin{array}{c}\text { M'Chigeeng } \\
\text { First Nation } \\
n=32\end{array}$ & $\begin{array}{l}\text { Whitefish River } \\
\text { First Nation } \\
n=40\end{array}$ & $\begin{array}{c}\text { Wiikwemkoong } \\
\text { Unceded Territory } \\
\quad n=124\end{array}$ \\
\hline Girls, no. (\%) & $14(44)$ & $19(48)$ & $69(56)$ \\
\hline Age, mean \pm SD (range); yr & $11.3 \pm 2.4(8-16)$ & $12.0 \pm 2.8(8-17)$ & $14.1 \pm 3.9(7-22)$ \\
\hline
\end{tabular}

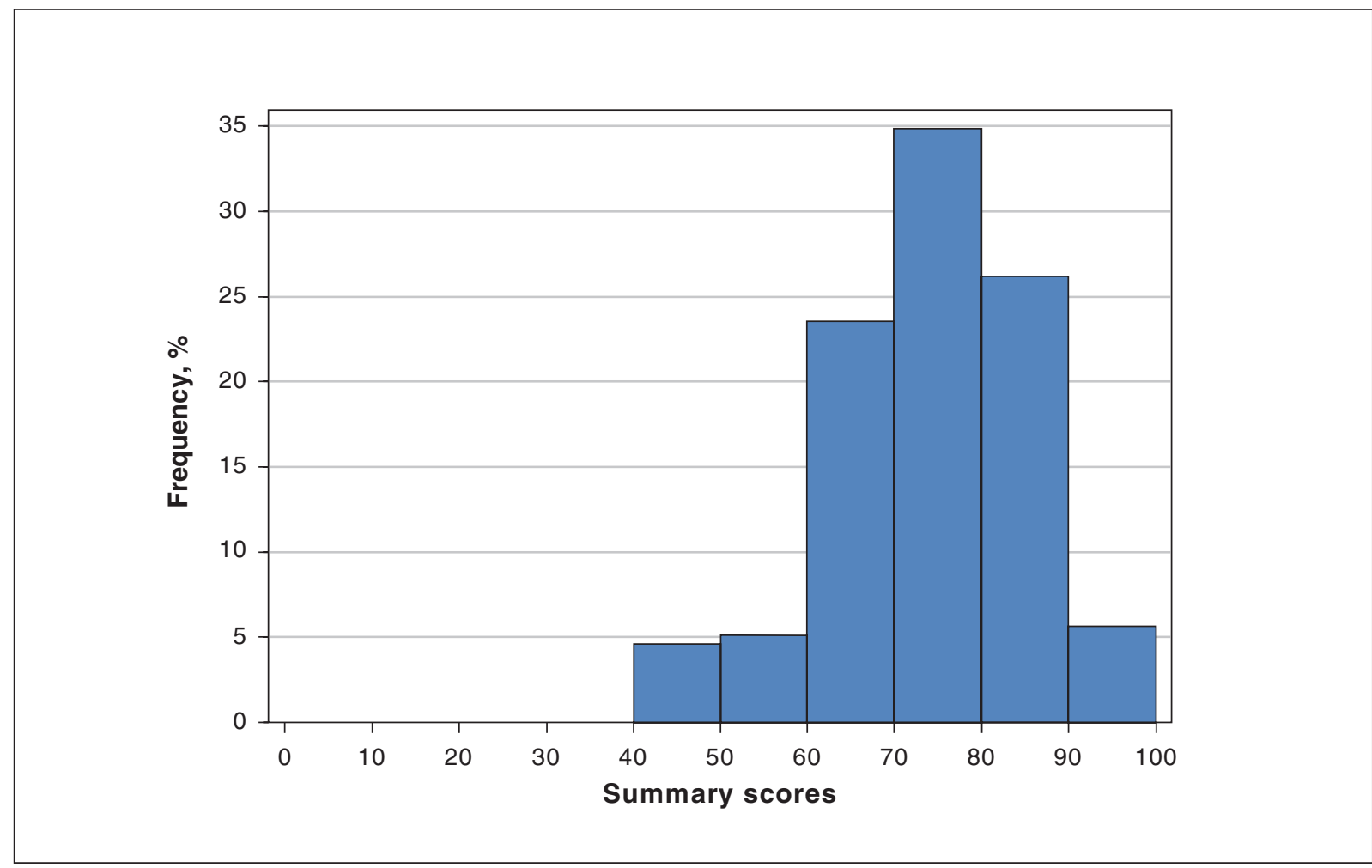

Figure 3: Aboriginal Children's Health and Well-Being Measure (ACHWM) summary score distribution. A score of 100 indicates optimal health. 
quadrant reflects the children's assessments of their thinking and problem solving (i.e., intellectual health or cognition), whereas the emotional quadrant reflects feelings, which western society considers to be "mental health." The distribution of the summary score and quadrant scores is shown in Figure 4.

\section{Additional exploratory analyses}

The ACHWM summary scores were found to be slightly lower among older children, decreasing by 0.7 points per year of age (95\% CI $0.26-1.13, p=0.002)$, but they did not differ between boys and girls. This slight age effect was apparent across all 4 quadrant scores, with a decrease of 1.1 point $(95 \%$ CI $0.53-1.61)$ per year of age for spiritual health, 0.54 point (95\% CI 0.02-1.06) for emotional health, 0.66 point (95\% CI $0.13-1.18$ ) for physical health and 0.49 point (95\% CI $0.12-$ 0.97 ) for mental health.

When we explored the balance within each participant, using the SD of the 4 quadrant scores, we observed balance scores that ranged from 1 to 24 , with a mean of 11.0 (SD 4.69, 95\% CI 10.3-11.7) and a median of 10.6. The distribution of balance scores is shown in Figure 5. There was no apparent variation in balance scores related to age or sex.

Although the main focus of using the ACHWM was to understand the health of First Nation children, the measure also afforded the opportunity to screen for emotional health concerns. The screening process allowed us to identify 33 children (16.8\% of participants) who were in need of further assessment and enabled the mental health workers to connect these children to ongoing supports within their home communities.

\section{Interpretation}

The results presented in this paper provide a health profile from a relatively large sample of First Nation children living on their traditional territories in rural Northern Ontario. The mean ACHWM summary score in this sample was 74 and the mean quadrant scores were 79 for spiritual health, 74 for emotional health, 77 for physical health and 62 for mental health. Thus, these children were strong spiritually and the greatest opportunity for improvement was in the mental health quadrant. According to the guidance of the medicine wheel, the mental quadrant focuses on thinking, reasoning and problem solving and could also be considered as an intellectual or cognitive domain. These scores reflect the strengths of the children in these communities. They may to some extent reflect a consent bias, in which children with the lowest health scores may not have participated in the survey.

It is difficult to put the ACHWM scores into context because there are limited health data from Aboriginal children reported in the literature. From the global health ratings in this sample, we know that $16 \%$ of our total study population and $14 \%$ of our subsample of youth aged 12 to 17 years reported being in excellent health. This is much lower than the $22.8 \%$ of First Nations youth (aged 12-17 yr) in Ontario who self-reported being in excellent health on the Regional Health Survey. ${ }^{4}$ Thus, the results reported here are significantly different from the Ontario Regional Health Survey results $(p<0.005)$, underscoring the importance of local data for planning purposes.

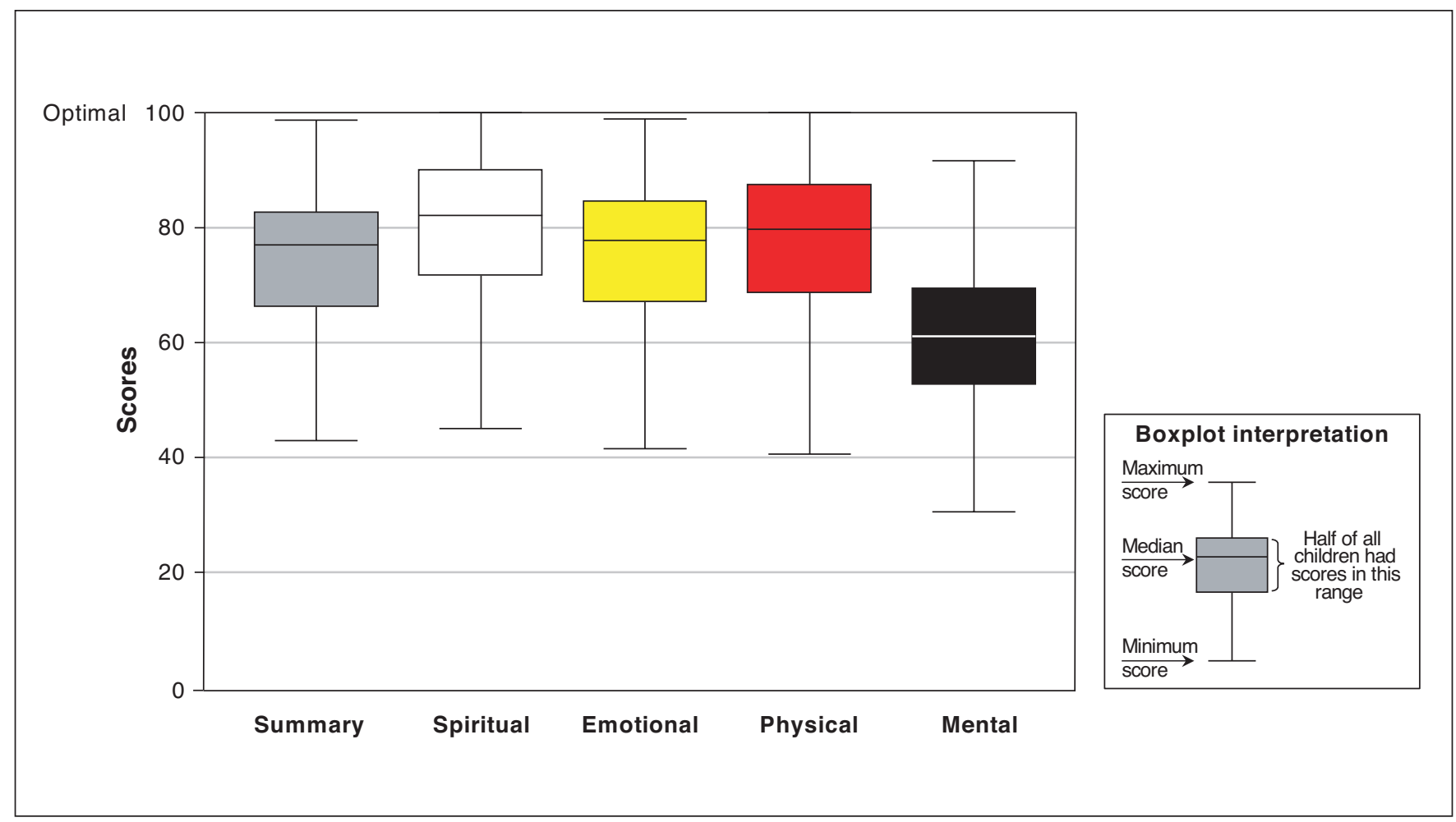

Figure 4: Distribution of ACHWM summary score and quadrant scores. A score of 100 indicates optimal health. Note: Outliers were suppressed to protect the confidentiality of participants. ACHWM = Aboriginal Children's Health and Well-Being Measure. 


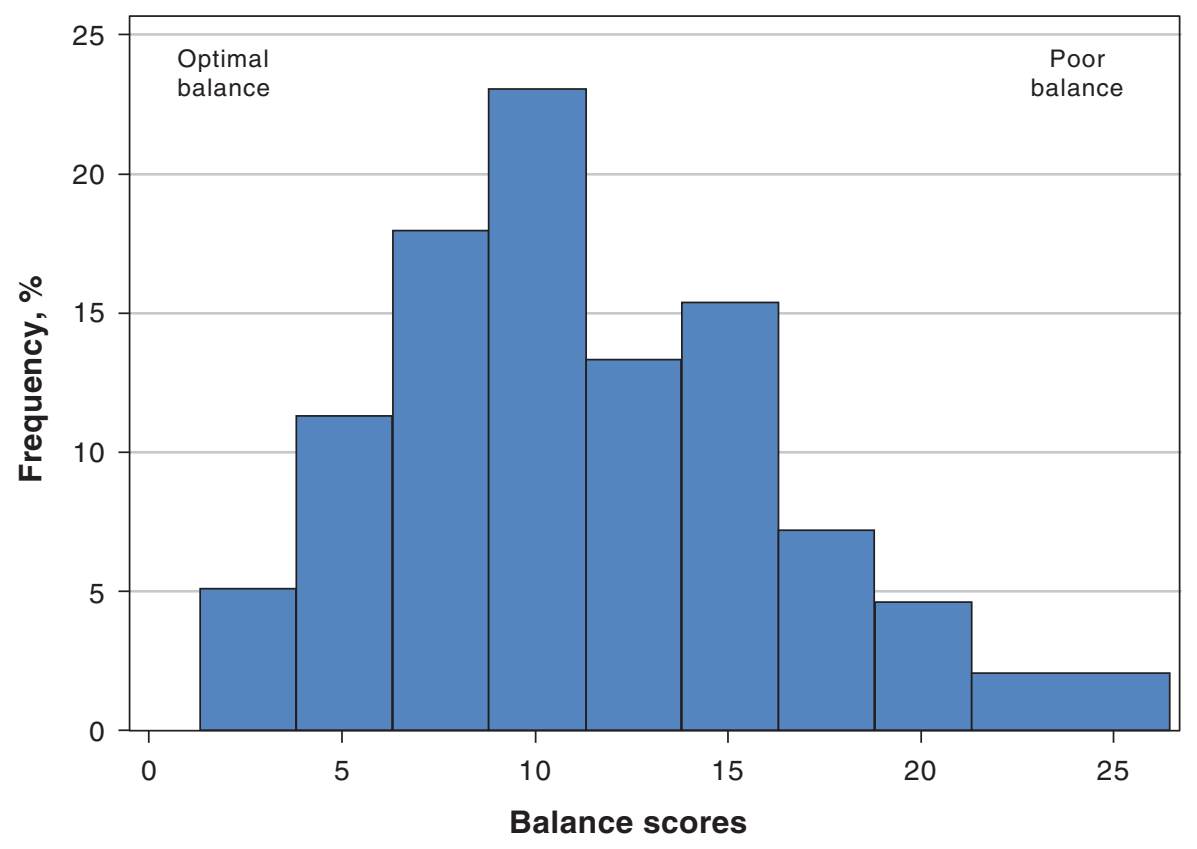

Figure 5: Distribution of balance scores.

It is also possible to compare the scores reported here with what we know on the basis of normative data from the PedsQL, which is a generic health-related quality of life measure for children. The interpretation of ACHWM scores is similar to the PedsQL scale $(r=0.51$ with a 0.3 -point difference between the PedsQL and ACHWM summary scores). ${ }^{24}$ We also know that the mean PedsQL score for an urban school-based population sample was 80.6 (SD 13.3). ${ }^{25}$ Furthermore, Varni and colleagues' initial validation study of the PedsQL reported a mean total PedsQL score of 79.6 (SD 15.3) in a sample of 960 children 5 to 18 years of age. ${ }^{26}$ This suggests that rural First Nations children from the Manitoulin region have health scores that approach PedsQL norms. However, many children (16.8\% of participants) were newly identified as needing mental health services through this study. Thus, additional health and social supports are needed to address these apparent health inequities.

Finally, the exploration of balance offered a new opportunity to facilitate strengths-based conversations with children who completed the ACHWM and an additional type of information to guide the planning of community programs and services.

\section{Limitations}

This research has several limitations. Our sample comprised approximately $25 \%$ of the children in each of 3 communities and thus may be considered a sample of convenience. As such, scores may be slightly elevated. The data came from 3 rural First Nations in close proximity and thus have produced a local estimate. Our statistical computation of balance is new and requires further exploration. Finally, the sample did not include Inuit or Métis children. Despite these limitations, we are confident that these results add substantially to what we know about Aboriginal children's health. We are eager to see results from other populations and examine how they compare with these profiles.

\section{Conclusion}

The ACHWM is a new, culturally relevant, child-reported outcome measure that should be considered as a potential population health assessment tool for Aboriginal communities. The profiles reported here provide an initial estimate to understand how First Nations children living on their traditional territory in Northern Ontario perceive their health. These initial profiles establish benchmarks against which these and other communities may assess changes over time. The information presented in this paper may also support program evaluation within Aboriginal communities, enable communities to learn from one another and promote the creation of new knowledge that is relevant to Aboriginal communities. In doing so, these communities may identify best practices that may contribute to better child health in the future.

\section{References}

1. Sackett DL, Rosenberg WMC, Gray JAM, et al. Evidence based medicine: what it is and what it isn't. BMF 1996;312:71-2.

2. Adams J, Broom A, editors. Evidence-based healthcare in context: critical social science perspectives. New York: Routledge Taylor \& Frances; 2016.

3. MacMillan HL, Walsh CA, Jamieson E, et al. The health of Ontario First Nations people: results from the Ontario First Nations Regional Health Survey. Can 7 Public Health 2003;94:168-72. 
4. Chiefs of Ontario. First Nations Regional Health Survey (RHS) Ontario Region Phase 2 (2008/10): people's report. Toronto; 2014.

5. Guèvremont $A$, Carriere $G$, Bougie $E$, et al. Acute care hospitalization of Aboriginal children and youth. Health Rep 2017;28:11-7.

6. Population Health Assessment LDCP Team. Children count: assessing child and youth surveillance gaps for Ontario Public Health Units. Windsor (ON): Public Health Ontario; 2017.

7. Smylie J, Anderson M. Understanding the health of Indigenous Peoples in Canada: key methodological and conceptual challenges. CMAF 2006;175:602-5.

8. Smylie J, Adomako P. Indigenous cbildren's health report: bealth assessment in action. Toronto: St. Michael's Hospital; 2009. Available: http://stmichaelshospitalresearch. ca/research-programs/urban-health-solutions/resources-and-reports/indigenous -childrens-health-report-health-assessment-in-action/ (accessed 2010 Aug. 21).

9. Ball J. Promoting equity and dignity for Aboriginal children in Canada. IRPP Choices 2008:14:1-32.

10. Canadian UNICEF Committee. Canadian supplement to the state of the world's children 2009: Aboriginal children's health: leaving no child behind. Toronto: UNICEF Canada; 2009. Available: http://www.unicef.ca/sites/default/files/ imce_uploads/DISCOVER/OUR\%20WORK/ADVOCACY/DOMESTIC/ POLICY\%20ADVOCACY/DOCS/Leaving\%20no\%20child\%20behind\% 2009.pdf (accessed 2019 Mar. 22).

11. Together we are ... feathers of hope: a First Nations youth action plan. Toronto: Office of the Provincial Advocate for Children and Youth; 2014.

12. Honouring the truth, reconciling for the future: summary of the final report of the Truth and Reconciliation Commission of Canada. Winnipeg: Truth and Reconcilation Commission of Canada; 2015.

13. Young NL, Wabano MJ, Burke TA, et al. A process for creating the Aboriginal Children's Health and Well-Being Measure (ACHWM). Can 7 Public Health 2013;104:e136-41.

14. Dumont J. First Nations regional longitudinal health survey (RHS) cultural framework. Ottawa: First Nations Information Governance Committee; 2005.

15. Young NL, Wabano MJ, Blight S, et al. Relevance of the Aboriginal Children's Health and Well-being Measure (ACHWM) beyond Wikwemikong. Rural Remote Health 2017:17:3941.

16. Young NL, Jacko D, Wabano MJ, et al. A screening mechanism to recognize and support Aboriginal children at-risk: based on a child-centric survey. Can 7 Public Health 2016;107:e399-403.

17. Saylor K, Blackstock C. Many hands, one dream: healthy Aboriginal children and young people. Paediatr Child Health 2005;10:523-4.

18. Young NL, Wabano MJ, Usuba K, et al. Validity of the Aboriginal children's health and well-being measure: Aaniish Naa Gegii? Health Qual Life Outcomes 2015;13:148-56.

19. Young NL, Wabano MJ, Usuba K, et al. Reliability of the Aboriginal Children's Health and Well-Being Measure (ACHWM). Springerplus 2016;5:2082-7.

20. Harris PA, Taylor R, Thielke R, et al. Research electronic data capture (REDCap) - a metadata-driven methodology and workflow process for providing translational research informatics support. 7 Biomed Inform 2009;42:377-81.

21. Tractenberg RE, Pietrzak RH. Intra-individual variability in Alzheimer's disease and cognitive aging: definitions, context, and effect sizes. PLoS One 2011;6:e16973.

22. Maar MA, Sutherland M, McGregor L. A regional model for ethical engagement: the First Nations Research Ethics Committee on Manitoulin Island. APRCi 2007;4:55-68. Available: http://ir.lib.uwo.ca/aprci/112 (accessed 2018 July 12).
23. Census program 2011. Ottawa: Statistics Canada; modified 2019 Mar. 20. Available: http://www12.statcan.gc.ca/census-recensement/index-eng.cfm (accessed 2017 Aug. 17).

24. Young NL, Wabano M-J, Pangowish B, et al. Validity of the Aboriginal Children's Health and Well-Being Measure (Aaniish Naa Gegii) - published abstract from the International Society for Quality of Life Annual Conference. Qual Life Res 2014;23(Suppl):174.

25. Varni JW, Burwinkle TM, Seid M. The PedsQL 4.0 as a school population health measure: feasibility, reliability, and validity. Qual Life Res 2006; 15:203-15.

26. Varni JW, Seid M, Kurtin PS. PedsQL 4.0: reliability and validity of the Pediatric Quality of Life Inventory version 4.0 generic core scales in healthy and patient populations. Med Care 2001;39:800-12.

27. MacMillan HL, Jamieson E, Walsh C, et al. The health of Canada's Aboriginal children: results from the First Nations and Inuit Regional Health Survey. Int 7 Circumpolar Health 2010;69:158-67.

Affiliations: Naandwechige Gamig Wikwemikong Health Centre (Wabano, Jacko, Mishibinijima), Wiikwemkoong Unceded Territory, Ont.; Whitefish River First Nation (L.F. McGregor, L.E. McGregor), Ont.; M'Chigeeng First Nation (Beaudin, Kristensen-Didur), Ont.; ECHO Research Centre (Usuba, Young), Laurentian University, Sudbury Ont.

Contributors: Mary Jo Wabano, Leslie McGregor, Roger Beaudin, Diane Jacko, Lorrilee McGregor, and Nancy Young participated in the study design. Sabine Kristensen-Didur and Debbie Mishibinijima collected data for this study. Mary Jo Wabano, Nancy Young and Koyo Usuba participated in the analysis and wrote this paper. All authors revised the paper for important intellectual content, approved of the final version to be published and agreed to be accountable for all aspects of the work.

Acknowledgements: The authors are extremely grateful to the members of the Wiikwemkoong Unceded Territory, M'Chigeeng First Nation and Whitefish River First Nation who have contributed to this project over several years, by offering their experience, insights and critical guidance. These include Elder Rita Corbiere and others. The authors express thanks to the children who participated in the surveys and all 3 communities for their support of this project.

Funding: Funding for the 3 community surveys included in this study was provided by a Health System Research Fund grant (2013-2016) and funding for the pooled analysis was provided by a Health System Research Fund grant (2017-2020) from the Ontario Ministry of Health and Long-Term Care.

Supplemental information: For reviewer comments and the original submission of this manuscript, please see www.cmajopen.ca/content/7/2/ E316/suppl/DC1. 